\title{
Research on Cassava Drying, Application and Promotion of the Reversible Airflow Flatbed Dryers for Sliced Cassava
}

\author{
Tran Van Tuan, Le Quang Vinh and Nguyen Van Xuan \\ Center for Agricultural Energy and Machinery, Nong Lam University, Ho Chi Minh City 700000, Vietnam
}

\begin{abstract}
The study was conducted by researchers of the Research Center for Agricultural Energy and Machinery (CAEM) of the Ho Chi Minh City Nong Lam University (NLU) with the objectives of researching on drying ways for cassava and of evaluating the adaptability of the reversible-airflow dryers in drying of cassava. The results obtained were as follows: done with thin-layer drying experiments, deep-layer drying experiments in the lab, and conducted drying experiments at the cassava dryer in actual production scale with two capacity sizes of 8 tons/batch and 16 tons/batch, that operates based on principle of reversible-airflow drying (SRA dryers). By the means of drying experiments, the performance of the SRA dryers such as optimal drying temperature, drying time, drying airflow reversal timing, moisture content uniformity of the sliced cassava mass after finishing drying process, drying cost, etc. was defined, the optimal drying temperature was $70{ }^{\circ} \mathrm{C}$, the total actual drying time for finishing one batch was $25-28$ hours, applicable time for drying airflow reversal was after drying 16 hours since startup, the deviation in moisture content of the cassava mass after drying was just 2\%-3\%, the drying costs (per one kg of dried cassava) calculated were in turns VND407/kg at the SRA-8 dryer (8 tons/batch), and VND351/kg at the SRA-16 dryer (16 tons/batch). Obviously, comparing with the sale price of dry cassava at present, these levels of drying cost are accounting for 7\%-10\%, which are suitable and acceptable. Thus, investment of the dryers for sliced cassava would be effective and contribute to bring more income for Vietnamese cassava farmers and dryer end-users.
\end{abstract}

Key words: Cassava, sliced cassava, SRA dryer, wood-chip furnace.

\section{Introduction}

Cassava is a popular plant in tropical regions, and ranked 4th among the food crops after rice, maize, and wheat in developing countries. Cassava starch is an important component in human regimen, and cassava is also a commercial plant type that is valuable in processing for food. One of outstanding applications of cassava now and in the future is for producing biofuel (a kind of environmental-friendly fuel) to be used in the internal-combustion engines.

Vietnam is one of top cassava starch exporter in the world, ranked 2nd right after Thailand. According to Ref. [1], in 2013, the cassava area of Vietnam was 544.1 million ha, and its total production was about 9.74 million tons. In recent years, in Vietnam, cassava

Corresponding author: Le Quang Vinh, researcher, research field: crop postharvest engineering. has really become a commercial crop that contributes greatly to the poverty alleviation movement for farmers in remote and upland areas. Since cassava starch has become a kind of material for producing ethanol, it has marked a milestone in the development history of this crop. Therefore, the cassava is more and more valuable and has been becoming a crop as priority to be researched and developed in the strategic vision of the country.

For this reason, the solutions of cassava promotion to create competitive advantages on the market, apart from production factors such as variety, cultivation technique, crop management, harvesting, etc. deep investment in postharvest processing technologies is decisional in maintaining cassava production and in enhancing the value of cassava exports. Of which, postharvest preliminary processing stage (in sliced cassava production) plays an important role in 
improving cassava quality and in reducing price, and most salient stage is drying. Since harvesting season is usually right at peak of rainy season, drying of agro-products (popular method is sun drying) is frequently facing contingencies due to erratic weather conditions, that may deteriorate agro-products. This is unavoidable fact if farmers are still dependent on natural energy source (solar energy). From that practical demands, the Center for Agricultural Energy and Machinery researched and applied dryers to the cassava preliminary processing in order to reduce production cost, and then to bring more income for cassava farmers.

The objectives of the study are to evaluate the adaptability of the reversible-airflow flatbed dryer in drying of cassava, and then to present another option of drying technology to be applied to the cassava preliminary processing in Vietnam.

\section{Materials and Methods}

With the aim of defining geometrical parameters of the actual dryer as well as selecting appropriate parameters of drying regime (drying temperature, required air volume, etc.), drying experiments with a lab dryer (Fig. 1) for sliced cassava are very necessary.

\subsection{Lab Dryer}

The lab dryer for sliced cassava (Fig. 1) used in the study has main components as follows:

(1) Drying bin: containing drying trays inside, which is designed to operate following the principle of air reversal;

(2) Dryer fan: it is a centrifugal fan to produce air for drying process;

(3) Heater: it is a resistance box, the drying temperature is controlled by an automatic control system;

(4) An automatic temperature recording system connected with a computer, or recorded manually.

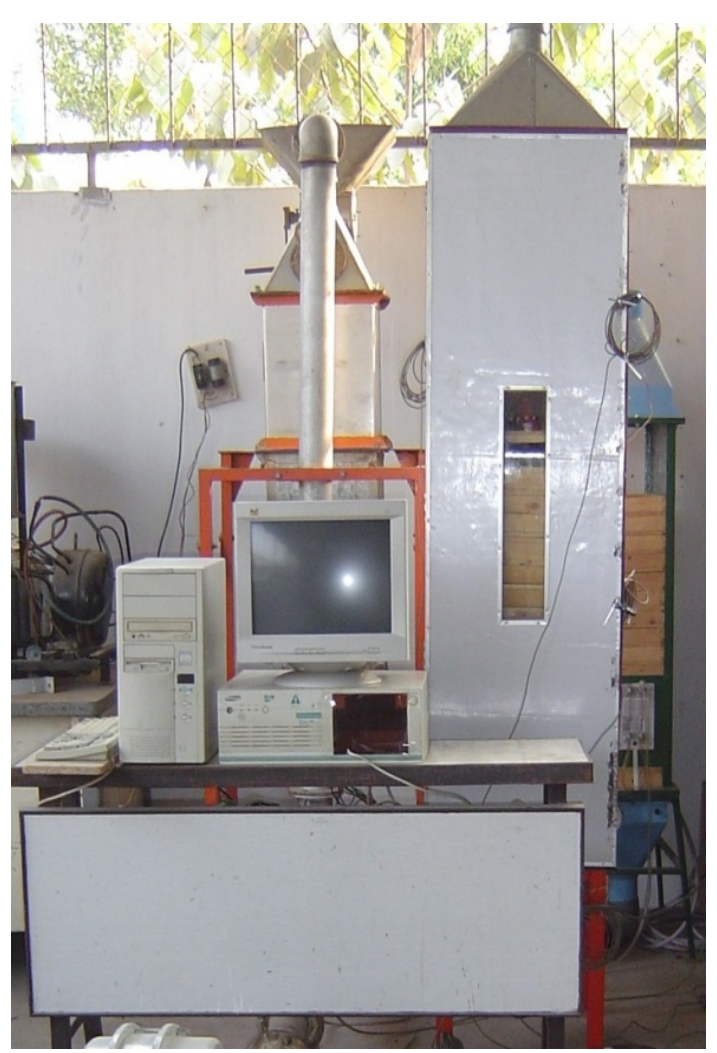

Fig. 1 The lab dryer.

\subsection{The SRA Dryer for Sliced Cassava in Production Scale}

The reversible airflow flatbed dryers were designed by the NLU, fabricated and applied to various types of agro-products such as paddy, maize, sliced cassava, pepper, coffee, peanut, etc. with outstanding advantages in drying product quality and drying cost [2].

The sliced cassava dryer in practical production scale with operating principle and perspective diagram shown in Fig.s 2 and 3, has main components and specifications as follows:
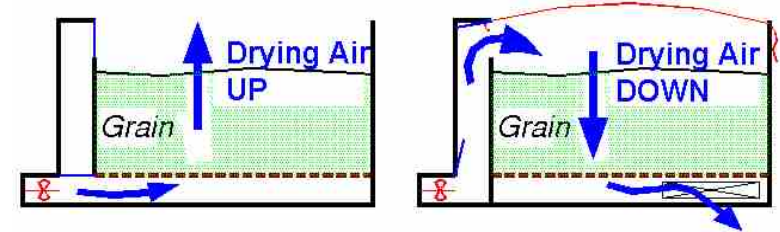

Fig. 2 Principle of air reversal drying. 


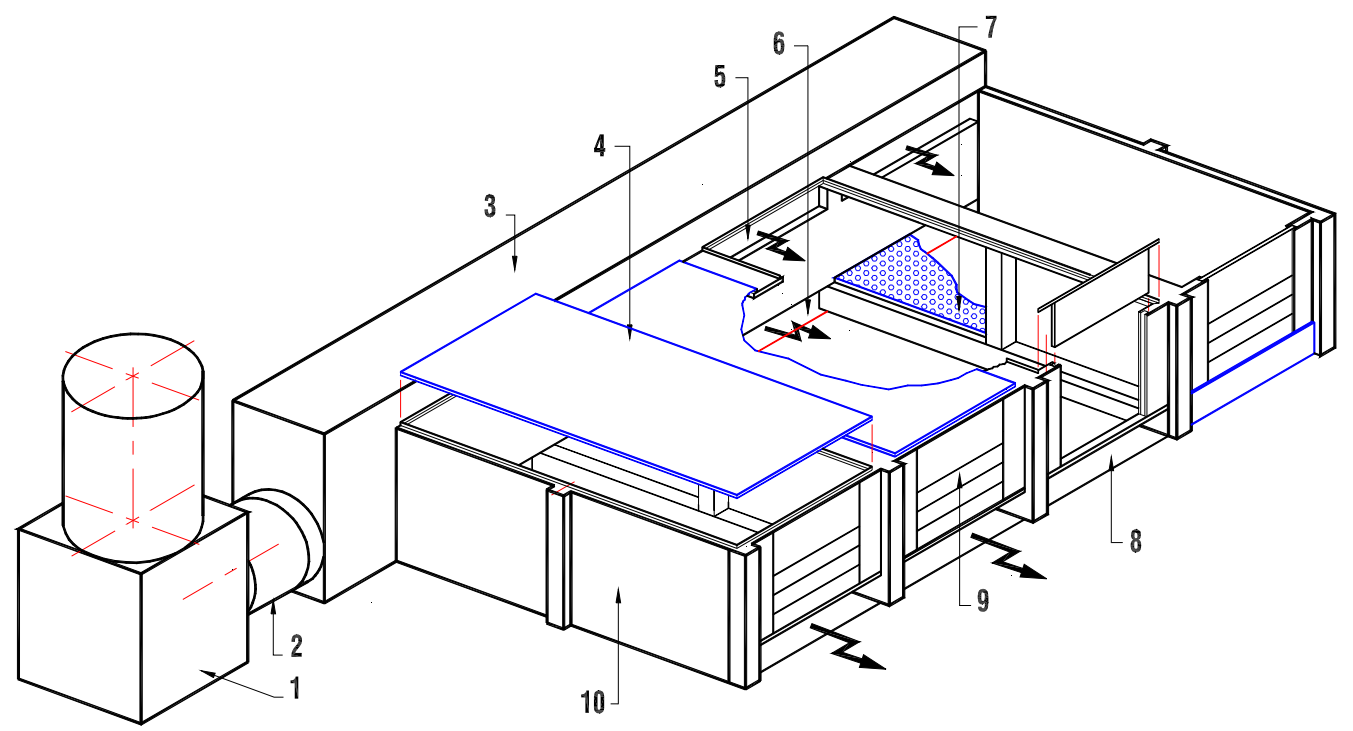

Fig. 3 Perspective diagram of reversible airflow flatbed dryer for sliced cassava.

1-Woodchip furnace; 2-Dryer fan; 3-Side air duct; 4-Floor;5-Upper air duct; 6-Lower air duct; 7-Fasteners; 8-Drying bin entrances.

\section{Wood-chip furnace with a cylindrical combustion chamber}

This furnace model was designed based on principle of direct heat exchange and burning, it is similar to the cylinder-shaped wood-chip furnace model [3]. A direct-combustion furnace should meet requirements of clean flue gas, no fly ashes, sparks and smoke. The furnace with composition and technical parameters is appropriate for woodchip fuel and to be used for sliced cassava dryers. The furnace is capable of producing heat energy to supply to dryer with a drying temperature range of $60-70{ }^{\circ} \mathrm{C}$, designed in two wood chip fuel consumption rates of $60 \mathrm{~kg} / \mathrm{h}$ and $120 \mathrm{~kg} / \mathrm{h}$ for SRA-8 dryer and SRA-16 dryer, respectively.

Dryer fan: The fan used at this dryer is a 2-stage axial-tube fan with good performance, which could produce enough air volume required in drying process at this dryer corresponding to an unit air volume of $0.6-0.7 \mathrm{~m}^{3} / \mathrm{s} /$ ton of drying material at a static pressure of $25-35 \mathrm{~mm} \mathrm{H}_{2} \mathrm{O}$. The fan is drawn by a $7.5-\mathrm{kW}$ electric motor (or 15-HP diesel engine) for the SRA-8 dryer, and by a 15-kW electric motor (or 28-HP diesel engine) for the SRA-16 dryer. The fan is tested relying on a fan testing standard before installing in a drying system [4].

Drying chamber: is flatbed and box-shaped type (Figs. 2 and 3), drying bed is perforated sheets (4) for putting drying materials, it is designed appropriately for both upward and downward drying.

Other components are including one canvas, canvas fasteners, and thermometers.

Method for determining and measuring reduction of cassava moisture content during drying process

Positions marked from 1 to 6 in drying bed (Fig. 4) were selected for sampling, and this activity was taken 5 times during drying process. At each position, cassava samples at layers of top, middle, and bottom would be taken for defining moisture content by time. The reduction of cassava moisture content by time would be defined as follows: at each experiment, weighing the cassava sample for its initial weight, then weighing the cassava sample in drying process for the its weight by time; lastly, the sample taken at the termination of drying process would be putting into an drying oven set up at a temperature of $103{ }^{\circ} \mathrm{C}$ in 72 hours [5] for removing completely moisture in the samples; then weighing the remaining dry matter. 


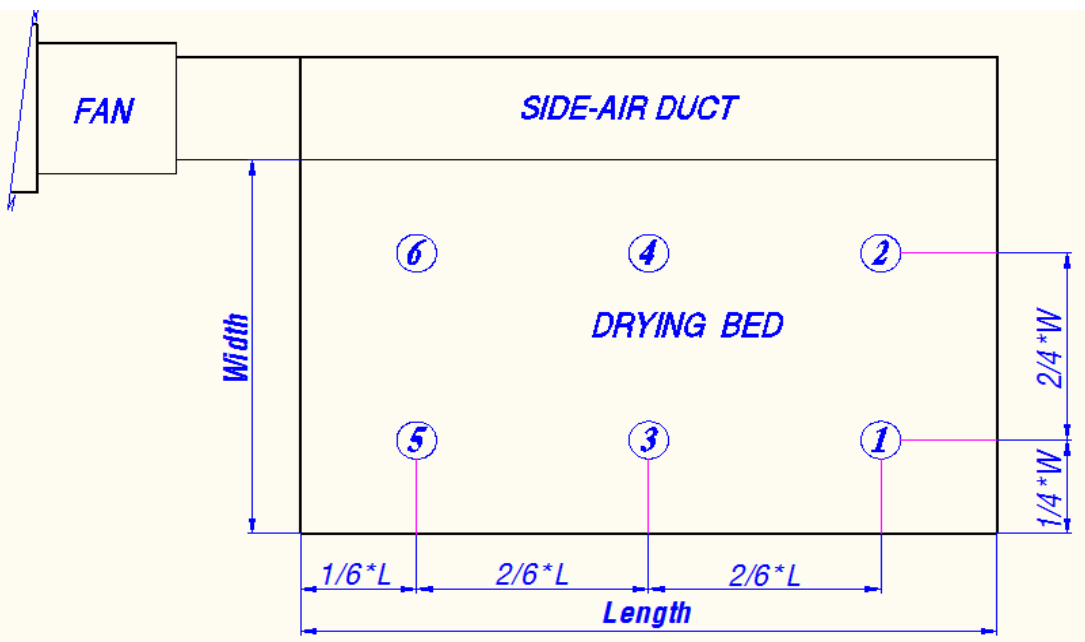

Fig. 4 Diagram of sample-taken positions.

Table 1 Parameters as doing thin-layer drying at the lab dryer.

\begin{tabular}{llll}
\hline Particulars & Batch 1 & Batch 2 & Batch 3 \\
\hline $\begin{array}{l}\text { Initial weight of cassava, g } \\
\text { Drying temperature applied, }{ }^{\circ} \mathrm{C}\end{array}$ & 2,413 & 2,392 & 2,263 \\
- In first 6 hours of drying process, ${ }^{\circ} \mathrm{C}$ & & 50 & 70 \\
$\quad$ In the rest of drying process, ${ }^{\circ} \mathrm{C}$ & 60 & 70 & 0.002 \\
Air volume, $\mathrm{m}^{3} / \mathrm{s}$ & 0.002 & 0.002 & 907 \\
Final weight of cassava, g & 946 & 950 & 13.0 \\
Moisture content of cassava after drying, $\%$ & 12.3 & 12.5 & 17 \\
Drying time, hours & 12.5 & 16 & 16 \\
\hline
\end{tabular}

From this value, the drying rate and the moisture content reduction of cassava sample during the dying process could be defined. Data analysis and statement would be based on the mean values.

\section{Results and Discusion}

\subsection{Results of Drying Cassava in the Lab [6]}

\subsubsection{Results of Thin-Layer Drying}

Through 3 thin-layer drying batches with detailed results presented in Table 1, moisture reduction process of sliced cassava samples (Fig. 5), and some following conclusions derive from:

- Mean initial moisture content of cassava is about $65 \%$ wb. Cassava sample used in the experiment 1 was premature cassava, but its initial moisture content was still reaching $65.7 \%$ wb. Then, the initial MC of cassava is not depending on harvesting time.

- Experiments were conducted with 20-mm thick cassava slices. The total drying time was shorter at the batch 1 , this might be because the skin layer of premature cassava is thinner and its flesh is spongier and softer, that leaded to moisture inside cassava sample was easily evaporating.

- In Batch 2 \& Batch 3, cassava samples used for the experiments were same and had the similar harvesting time. Batch 2 and batch 3 had different

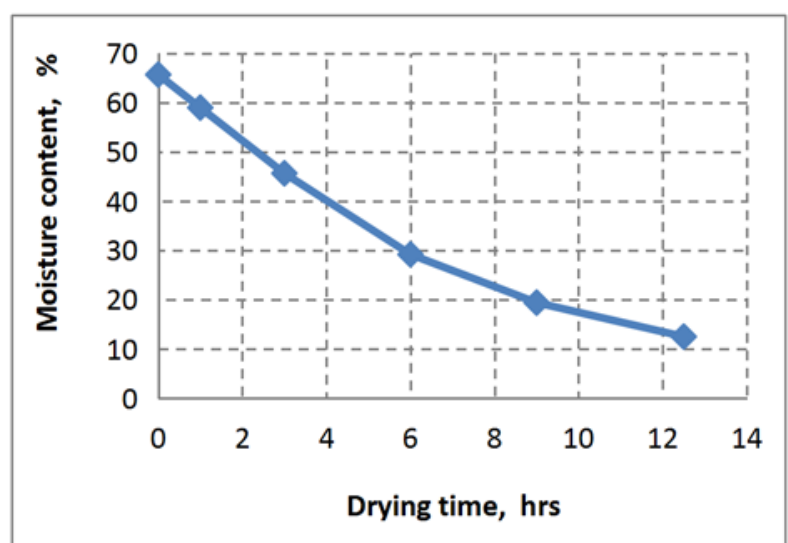

Fig. 5 Moisture reduction process of sliced cassava in Batch 1 at thin-layer drying experiment. 
Table 2 Parameters as doing deep-layer drying at the lab dryer.

\begin{tabular}{lll}
\hline Particulars & Batch 1 & Batch 2 \\
\hline Initial weight of cassava, kg & 10.14 & 7.23 \\
Weight of dried cassava, kg & 4.0 & 2.73 \\
Initial moisture content of cassava, \% & 65 & 65.3 \\
Moisture content of dried cassava, \% & 11.07 & 7.9 \\
Thickness of cassava layer, m $^{\circ}$ & 0.5 & 0.5 \\
Mean drying temperature, ${ }^{\circ} \mathrm{C}$ & 69.9 & 70.2 \\
${\text { Standard deviation in temperature, }{ }^{\circ} \mathrm{C}}^{\text {Unit air volume, }\left(\mathrm{m}^{3} / \mathrm{s} / \text { ton } \text { of drying material) }\right.}$ & 1.6 & 1.4 \\
Static pressure level, mmH $_{2} \mathrm{O}$ & 0.6 & 1.2 \\
Timing for doing air reversal, (after number of drying hours from the startup) & 20 & 28 \\
Total drying time, hours & 24 & 10 \\
\hline
\end{tabular}

drying regime; in the first 2 drying hours, moisture reduction rate of cassava at 2 experiments was almost equivalent. However, the drying times at these drying batches are not much different.

- Dried cassava product is aromatic, cassava slices surface has some white powder. Dry cassava slices of batch 1 are shrunk, outer cover layer of the dried cassava slice is wrinkled and got yellow.

- Dried cassava samples at batch 2 and batch 3 were rather similar; cassava slices were not shrunk, and outer cover layer of the dried cassava slice was grey and a bit wrinkled.

\subsubsection{Results of Deep-Layer Drying}

Through 2 experiments with similar conditions such as: drying temperature was $70{ }^{\circ} \mathrm{C}$, layer of drying material was $0.5 \mathrm{~m}$, and cassava slice was about 20 $\mathrm{mm}$ in thick, results revealed that drying temperature of $70{ }^{\circ} \mathrm{C}$ did not affect characteristic of the dried cassava slices; actual drying time of batch 1 lasted longer than that of batch 2 because air volume applying in batch 1 was just $1 / 2$ of that in batch 2 (see Table 2 for detailed drying data). High uniformity in moisture content of cassava mass among (top, middle, and bottom layers after drying was reached, it is noticed that this is an important criteria for evaluating the quality of drying and performance of the dryer.

\subsection{Application of Cassava Dryers to Production Scale}

Relying on obtained results of drying the sliced cassava samples in the lab dryer (Fig. 6), the research team designed, and promoted dryer models to apply to the production scale with 2 capacity sizes of 8 tonnes/batch and 16 tonnes/batch.

3.2.1 Results of testing the cassava dryers in practical production scale

Detailed data of the experimental drying batches with sliced cassava at the two dryers in production scale (Figs. 7-10) are presented in Table 3 and summarized as follows:

- Total actual drying time to finish one batch at the SRA-8 dryer is 28 hours, static pressure of the whole system is $20-25 \mathrm{mmH}_{2} \mathrm{O}$. Mean drying temperature is $67.5^{\circ} \mathrm{C}\left( \pm 4.6^{\circ} \mathrm{C}\right)$, mean ambient temperature during drying process is $25.1{ }^{\circ} \mathrm{C}\left( \pm 3^{\circ} \mathrm{C}\right)$, mean moisture content of sliced cassava mass after drying is $14.1 \%$.

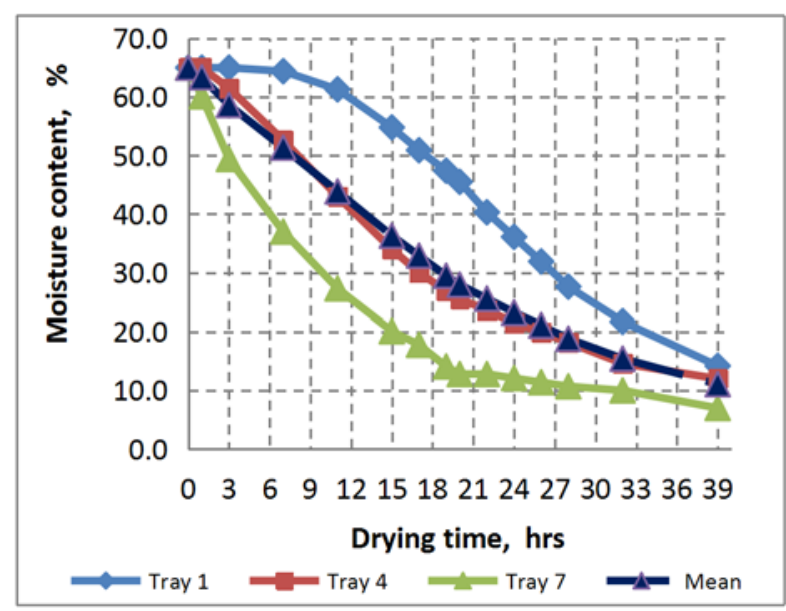

Fig. 6 Moisture reduction process of sliced cassava at a deep-layer drying batch at the lab dryer. 

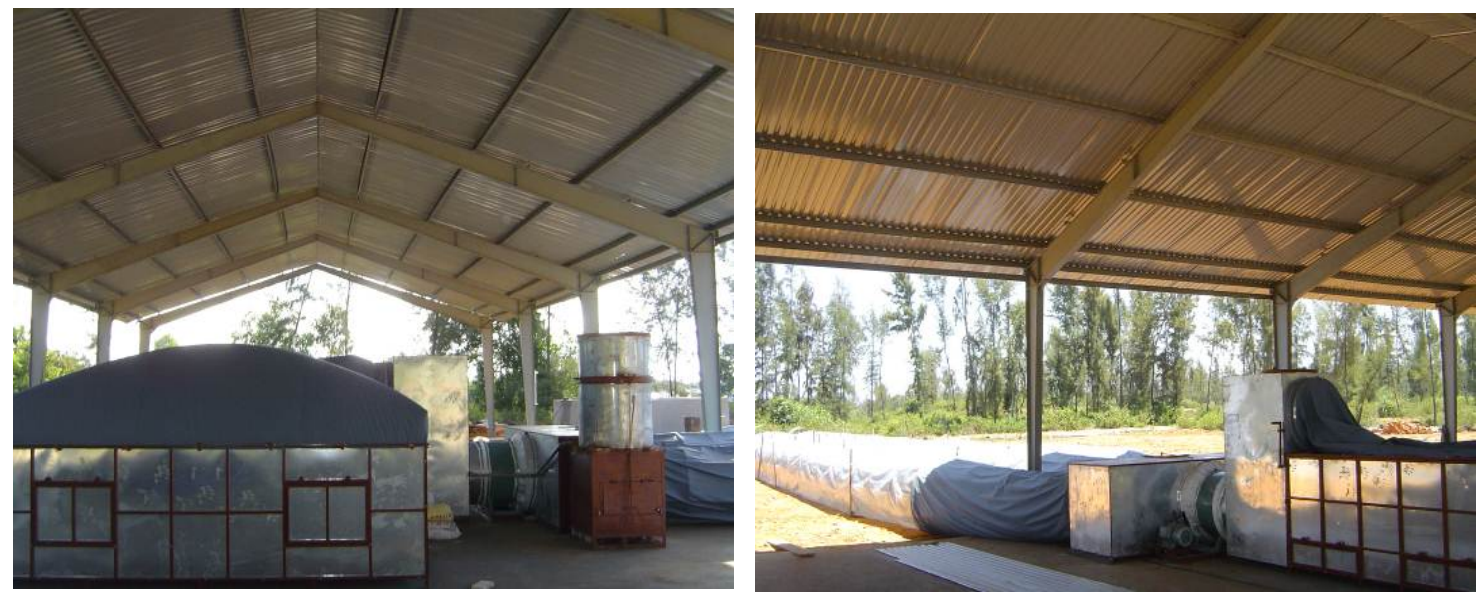

Figs. 7 and 8 The 8-ton/batch sliced cassava dryer (SRA-8) matching with a solar energy collector (at Ky Ha commune, Nui Thanh district, Quang Nam province).
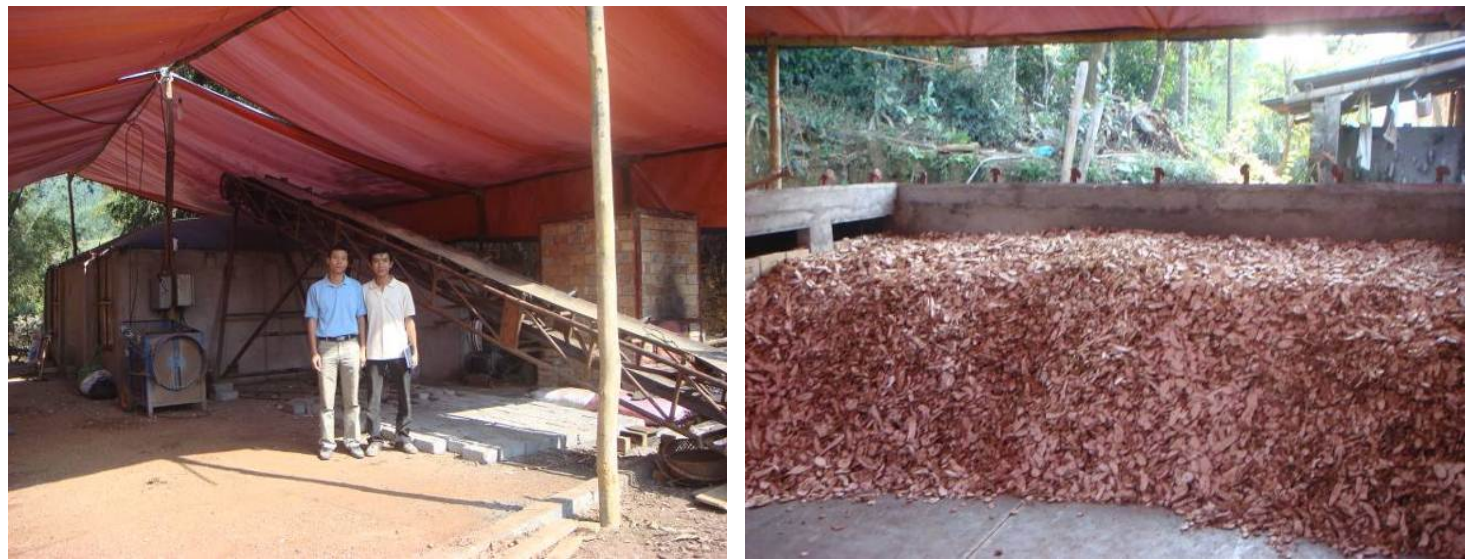

Figs. 9 and 10 The 16-ton/batch sliced cassava dryer (SRA-16) installed in Hoa Binh province.

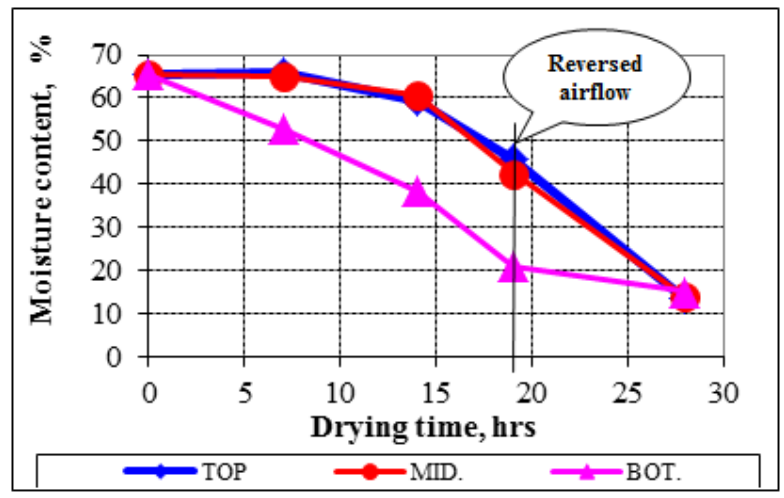

Fig. 11 Moisture reduction process of sliced cassava (TN1_SRA-8 dryer).

- Total actual drying time of the experimental drying batch at the SRA-16 dryer is 25 hours, static pressure of the whole system is $25-30 \mathrm{mmH}_{2} \mathrm{O}$. Mean drying temperature is $68.9^{\circ} \mathrm{C}\left( \pm 3.7^{\circ} \mathrm{C}\right)$, mean ambient temperature during drying process is $22.1^{\circ} \mathrm{C}$

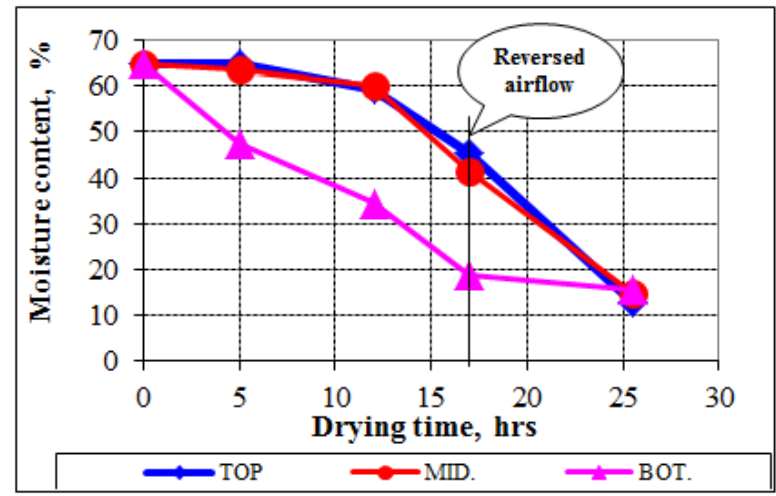

Fig. 12 Moisture reduction process of sliced cassava (TN3_SRA-16 dryer).

$\left( \pm 4.3{ }^{\circ} \mathrm{C}\right.$ ), mean moisture content of sliced cassava mass after drying is $14.3 \%$.

The two dryer models of SRA-8 and SRA-16 attained the design drying capacity and drying quality following quality criterion, and low non-uniformity in 
moisture content of cassava mass. The whole moisture reduction process at the two dryers was shown in Fig. s 11 and 12, and the air-reversal timing was done after around $2 / 3$ of total drying time from startup.

3.2.2 Economical Effectiveness as Applying the SRA Dryer for Sliced Cassava

Best effectiveness as applying SRA dryers for sliced cassava is a reduction in drying cost due to reducing cost of labor for dryer operation, cost of labor for mixing the drying material, and cost of land space for dryer installation. Detailed computations for cost of drying are shown in Table 4.

The cost of drying calculated based on actual data and initial assumptions as follows: the purchase prices are in turn VND110 million for the SRA-8 dryer, and VND210 million for the SRA-16 dryer; the life span of the dryers are 7 years; total annual drying capacities are 264 tons of dried cassava product (for the SRA-8 dryer), and 520 tons of dried cassava product (for the SRA-16 dryer). According to Ref. [7], the cost of drying for sliced cassava is VND407/kg of dry cassava product (for the SRA-8 dryer), while this is VND351/kg for the SRA-16 dryer (see Table 4 for more detailed). Among the components of the drying cost, the cost of labor is accounting for a significant ratio and much different between the dryers (see Figs. 13 and 14). The drying cost at the SRA-8 dryer is higher than that at the SRA-16 dryer that is because the total annual drying capacity at the SRA-8 dryer is lower, result in the depreciation cost is going up.

Practically, price of fresh cassava is popularly from VND1,300-VND1,400 per kg, selling price of dry cassava is around VND4,000 per $\mathrm{kg}$, and with a ratio of WET/DRY is $2.5 / 1$ (i.e. $2.5 \mathrm{~kg}$ of fresh cassava gets

Table 3 Results of testing the sliced cassava dryers of SRA-8 and SRA-16.

\begin{tabular}{|c|c|c|c|c|}
\hline \multirow{2}{*}{$\begin{array}{l}\text { Type of dryer } \\
\text { Experiment code }\end{array}$} & \multicolumn{2}{|c|}{ SRA-8 dryer } & \multicolumn{2}{|c|}{ SRA-16 dryer } \\
\hline & TN1 & TN2 & TN3 & TN4 \\
\hline Location & Quang Nam & Quang Nam & Hoa Binh & Hoa Binh \\
\hline With solar energy assisted & NO & YES & NO & NO \\
\hline Initial weight of fresh cassava, kg & 7950 & 8050 & 1570 & 1620 \\
\hline Initial MC of cassava sample, \% & 65.3 & 65.7 & 65.0 & 65.4 \\
\hline Mean MC of dried cassava, \% & 14.1 & 13.5 & 14.3 & 14.8 \\
\hline Standard deviation in MC, \% & 1.5 & 1.8 & 1.4 & 1.7 \\
\hline Thickness of sliced cassava layer, m & 0.8 & 0.8 & 0.8 & 0.8 \\
\hline Mean drying temperature, ${ }^{\circ} \mathrm{C}$ & 67.5 & 70.5 & 68.9 & 70.4 \\
\hline Air volume, $\mathrm{m}^{3} / \mathrm{s}$ & $\approx 5$ & $\approx 5$ & $\approx 10$ & $\approx 10$ \\
\hline Drying chamber static pressure, $\mathrm{mmH}_{2} \mathrm{O}$ & 20- 25 & 20- 25 & 20- 30 & 20- 30 \\
\hline Total drying time, hours & 28 & 25 & 25.5 & 25 \\
\hline $\begin{array}{l}\text { Timing for doing air reversal, (after number of } \\
\text { drying hours from start-up) }\end{array}$ & 19 & 17 & 17 & 16 \\
\hline Deviation in MC after drying, \% (max) & 2.5 & 2.4 & 2.7 & 2.3 \\
\hline Wood-chip consumption rate, $\mathrm{kg} / \mathrm{h}$ & 57.7 & 36.0 & 115.5 & 120.5 \\
\hline
\end{tabular}

Table 4 Drying costs as applying the SRA-8 dryer and the SRA-16 dryer.

\begin{tabular}{lllll}
\hline Type of dryer & \multicolumn{2}{c}{ SRA-8 dryer } & \multicolumn{2}{c}{ SRA-16 dryer } \\
\hline Components of drying cost & VND/kg of dried cassava & $(\%)$ & VND/kg of dried cassava & $(\%)$ \\
\hline Depreciation and Repair & 85 & 21.0 & 83 & 23.7 \\
Interest rate & 19 & 4.7 & 18 & 5.3 \\
Electricity (for drawing the fan) & 49 & 12.1 & 55 & 15.7 \\
Fuel (wood chip) & 95 & 23.3 & 106 & 30.1 \\
Labor & 156 & 38.3 & 86 & 24.5 \\
Land space hiring & 3 & 0.7 & 2 & 0.7 \\
Total & 407 & 100 & 351 & 100 \\
\hline
\end{tabular}




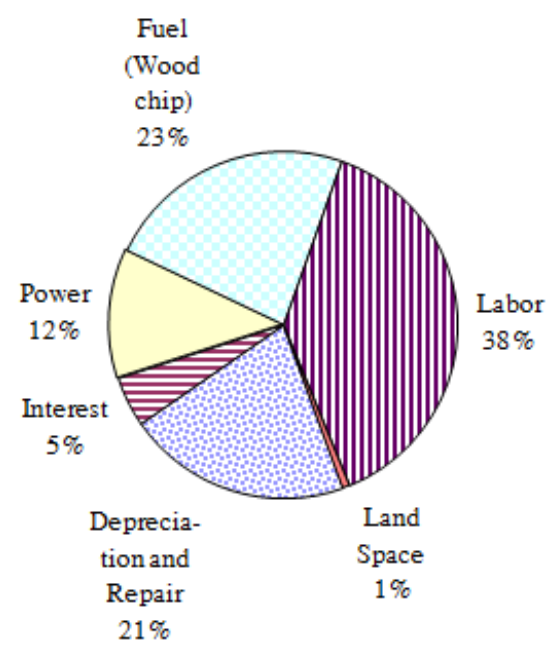

Fig. 13 Drying cost components in percent at the SRA-8 dryer.

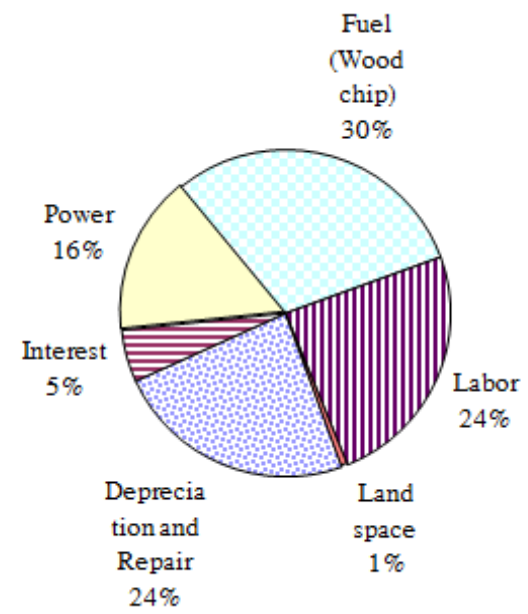

Fig. 14 Drying cost components in percent at the SRA-16 dryer.

$1 \mathrm{~kg}$ of dry cassava product), then adding the drying cost of VND350-VND400 per kg to production cost, now the production cost would be VND3,600VND3,650 per kg of dry cassava product. In that case, investing dryer for cassava preliminary processing is still effective and contributes to bring more income for cassava farmers.

On the other hand, drying of cassava (from initial $65 \% \mathrm{MCwb}$ ) requires much heat energy (i.e. cost of wood chip fuel is very much as well); therefore, if there is solar energy source (Figs. 7 and 8) assisted energy needed for drying process, then the cost of wood chip fuel would be lessened about $40 \%$, in this case, the cost of drying would be reduced about $15 \%-20 \%$.

3.2.3 Social effectiveness as applying the SRA dryer for sliced cassava

Comparing to manual drying for cassava (sun-drying method), number of labors required for operating the dryers SRA accounts for about 10\%. With the shortage of labor, improvement of mechanization level in drying operation is necessary and timely.

\subsection{Application of SRA Dryers for Sliced Cassava to Production Scale}

Up to July 2015, more than 10 dryers for sliced cassava with capacity of 8-30 tons/batch (where: 2/3 of which are the SRA dryers with the capacity of 16 tons/batch), operates based on the principle of air reversal and flatbed type, have been transferred and installed in various provinces in Vietnam such as Quang Nam, Daknong, Hoa Binh, Lam Dong, ... Feedbacks from customers about dried cassava quality and performance of the dryers showed that the drying products meet export criterion, ensure conditions for cattle-feed, and have an acceptable drying cost; that also means the dryers are proving their effectiveness, and have been accepted by users.

\section{Conclusions}

The objectives of the study set forth by the research team are reached, based on the result of drying cassava in the lab, the reversible airflow flatbed dryer models for sliced cassava are designed, fabricated, and applied effectively to the production scale, that meet requirements as follows:

- Moisture content of sliced cassava mass at the termination of drying operation is very uniform; dried cassava slices are not smoked, there are not fly ashes and sparks suck into the drying chamber.

- Simple in composition, acceptable in purchase price, easy in operation, and no labor required for 
mixing (or turning) the sliced cassava mass during the drying process.

- Drying cost levels are VND407/kg and VND351/kg for sliced cassava dried at the SRA-8 dryer and the SRA-16 dryer respectively; these are entirely acceptable.

There have been 10 units of this dryer model applied to the production scale in nationwide provinces so far, which is showing that the reversible-airflow flatbed dryer may be applied appropriately to drying sliced cassava and accepted by end-users. With the results obtained, the reversible-airflow flatbed dryer would be entirely a suitable option to the cassava preliminary processing, it contributes to reduce postharvest losses in the cassava production and bring more income for Vietnamese cassava farmers and dryer end-users.

\section{Acknowledgment}

Authors acknowledge to CAEM staffs for contributing efforts to the research, Dr. Phan Hieu Hien (Ex. Director of the NLU Center for Agricultural
Energy and Machnery) and his collaborators, who researched and promoted the Vietnamese reversible-airflow flatbed dryer model.

\section{References}

[1] GSO. 2014. Statistics Yearbook 2013. Statistics Publisher, Hanoi.

[2] Phan Hieu Hien, Nguyen Hung Tam and Nguyen Van Xuan. 2003. "The reversible air dryer SRA: One step to increase the mechanization of post-harvest operations.” In Proceedings of the international Conference on Crop Harvesting and Processing, 9-11 February 2003 (Louisville, Kentucky USA) ASAE Publication Number 701P1103e.

[3] Phan Hieu Hien, Nguyen Van Xuan, Nguyen Hung Tam, Le Van Ban and Truong Vinh. 2000. Grain Dryers in Vietnam. Ho Chi Minh City: Agricultural Publisher.

[4] JIS (Japanese Industrial Standard). 1968. Testing Methods for Fans and Blowers, JIS B-8330. Printed in Japan.

[5] ASAE (American Society of Agricultural Engineers). 1995. Yearbook 1994.

[6] Tran Duc Huy. 2008. Researching on Drying Sliced Cassava in the Laboratory. BSc. thesis, Nong Lam University, Ho Chi Minh City.

[7] ADB-IRRI RETA No. 6489 Rice Postharvest Project. 2010. Rice Postharvest Technology in Vietnam, p. 187: Paddy Drying. Ho Chi Minh City: Agricultural Publisher. 